\title{
The challenge of diagnosing 5alpha-reductase deficiency post gonadectomy
}

Dr Stephanie Miles, Dr Deborah Shears, Dr Brian Shine, Professor Ashley Grossman, Dr Aparna Pal Oxford University Hospitals NHS Foundation Trust, Oxford, United Kingdom

We present a case of a woman who was referred to Endocrinology as an adult having experienced virilisation in adolescence. The virilisation was managed with a gonadectomy prior to diagnosis of the underlying disorder. Here we discuss how gonadectomy altered the diagnostic approach, and lead to psychosocial challenges for the patient.

A woman of Pakistani origin moved to the United Kingdom aged 28 years. Aged 35 she underwent investigation for pyrexia of unknown origin; imaging demonstrated an absent uterus, and she was referred to Endocrinology.

Medical records from Pakistan had been destroyed. It was reported that she was born phenotypically female with normal female genitalia. During her late teenage years she experienced virilisation with deepening voice, increased pubic and axillary hair, and clitoromegaly; she had absent breast development.

Her parents were first cousins and her six siblings were unaffected.

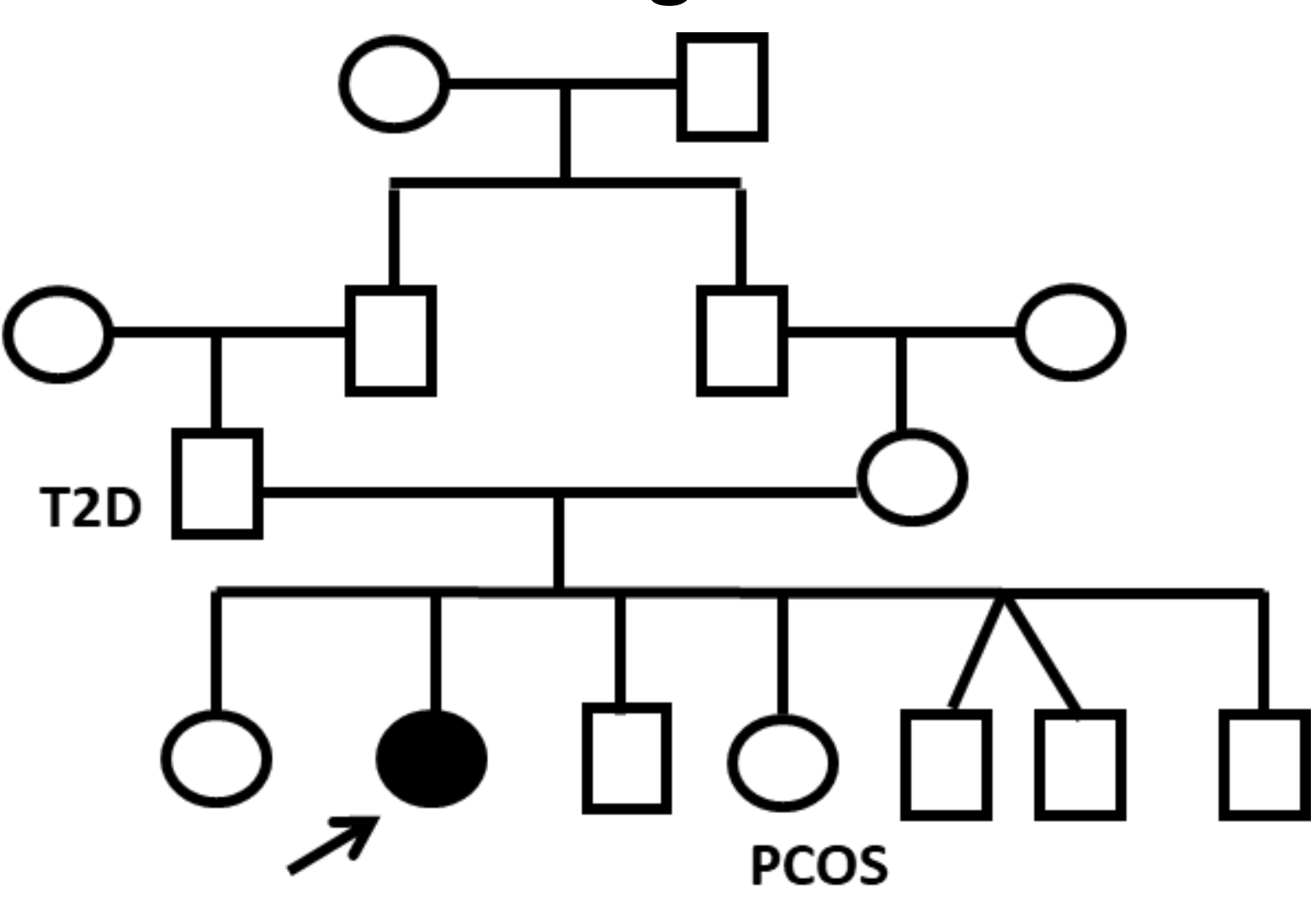

The patient reports that original investigations demonstrated a high testosterone and 'small ovaries and uterus'. She underwent the removal of a structure to her right labia majora as well as removal of a 'rudimentary uterus'. There was no surgery to the clitoris. Following surgery she did not receive ongoing medical care.

She had a socially difficult adolescence. At the time of virilisation she started to dress as a male. Following the surgery she identified as female. Due to gender identity issues she dropped out of university and a proposed marriage was broken off due to fertility concerns. She moved to the United Kingdom to resume her studies.

As an adult her examination demonstrated:

$\mathrm{BMI} 36 \mathrm{~kg} / \mathrm{m}^{2}$

Minimal facial, pubic and axillary hair

- Minimal breast tissue

Blind-ending vagina, clitoromegaly, and minimal breast tissue

Pelvic imaging confirmed absence of internal genitalia.

Hormonal evaluation revealed primary hypogonadism.

\begin{tabular}{|lc|c|c|}
\hline Assay & Result & $\begin{array}{c}\text { Normal range } \\
(\mathrm{M})\end{array}$ & $\begin{array}{c}\text { Normal range } \\
(\mathrm{F})\end{array}$ \\
\hline Testosterone (nmol/L) & 1.5 & $8.4-28.7$ & $0.5-2.6$ \\
\hline SHBG (nmol/L) & 77.4 & $13-71$ & $18-114$ \\
\hline Androstenedione (nmol/L) & 2.7 & $2.6-7$ & $3-9.6$ \\
\hline Oestradiol (pmol/L) & $<4.5$ & $0-191$ & $17-1470$ \\
\hline LH (U/L) & 14.9 & $3-8$ & $3-16$ \\
\hline FSH (U/L) & 50.4 & $1.4-18.1$ & $0.5-33$ \\
\hline 17-hydroxyprogesterone (nmol/L) & $<1.0$ & $1-8.7$ & $<18$ \\
\hline Prolactin (mU/L) & 63 & $45-375$ & $60-620$ \\
\hline TSH (mU/L) & 2.51 & $0.35-5.5$ & $0.35-5.5$ \\
\hline IGF-1 (nmol/L) & 23 & $14-47$ & $14-47$ \\
\hline Cortisol (nmol/L) & 136 & $180-620$ & $180-620$
\end{tabular}

Chromosomal analysis demonstrated a 46 XY karyotype.

Urinary steroid profile indicated 5alpha-reductase deficiency with

diagnostically low levels of the 5alpha-reduced metabolites relative to their 5beta-reduced counterparts.

\begin{tabular}{|l|c|c|c|}
\hline Steroid (ug/L) & Result & Mean & $\begin{array}{c}\text { Standard } \\
\text { Deviation }\end{array}$ \\
\hline Androsterone & 194 & 1526 & 520 \\
\hline Aetiocholanolone & 3124 & 1308 & 565 \\
\hline DHA & 1442 & 808 & 469 \\
\hline 11-oxo Aetiocholanolone & 482 & 625 & 329 \\
\hline 11-betahydroxy Androsterone & 100 & 855 & 244 \\
\hline 11-betahydroxy Aetiocholanone & 518 & 545 & 496 \\
\hline 16-alphahydroxy DHA & 3172 & 457 & 509 \\
\hline Androstenetriol & 2868 & 635 & 495 \\
\hline Tetrahydrocortisone & 4505 & 3137 & 1283 \\
\hline Tetrahydro-11-dehydrocorticosterone & 65 & 284 & 187 \\
\hline Tetrahydrocorticosterone & 238 & 208 & 100 \\
\hline Allo-tetrahydrocorticosterone & 110 & 323 & 122 \\
\hline Tetrahydrocortisol & 1615 & 1275 & 481 \\
\hline Allo-tetrahydrocortisol & 3 & 1205 & 509 \\
\hline
\end{tabular}

The SRD5A2 gene, which encodes 5alpha-reductase, lies on chromosome 2 p23. This was sequenced and screened for large scale deletions/duplications. A homozygous point mutation for $\mathrm{c} .698+1 \mathrm{G}>\mathrm{T}$ at the exon 4 /intron 4 boundary was found.

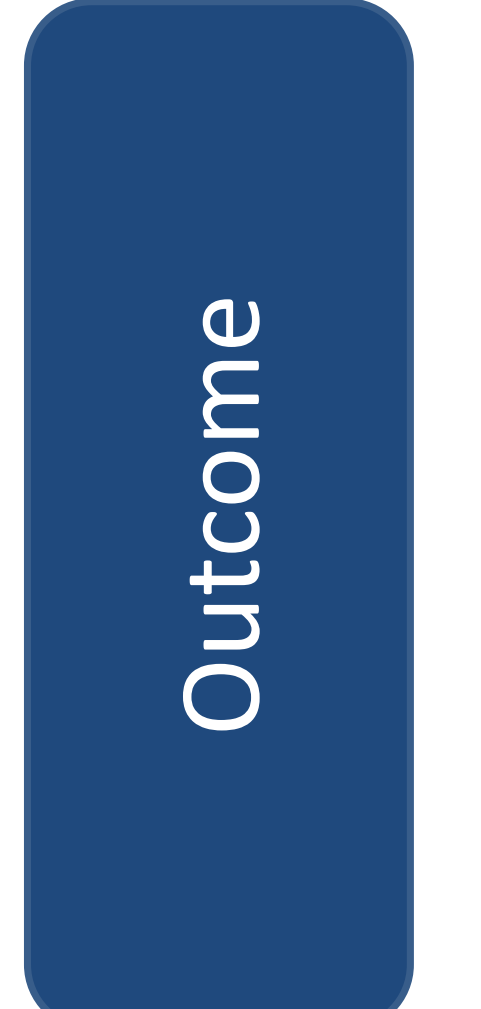

The patient elected to carry on living as a female and received psychological support.

She completed her studies in the United Kingdom and has continued her career in this country.

She was commenced on low dose ethinyloestrodiol which has increased her energy levels and led to breast development.

She has been offered a vaginoplasty but has turned this down.

Disorders of sexual development can present in a wide spectrum of presentations attributable to a number of disorders; commonly patients present with atypical genitalia at birth or during sexual development in adolescence(1). Presentation in adulthood and following gonadectomy is unusual(2).

Once the $46 \mathrm{XY}$ karyotype was established, differentiating between the key differential diagnoses of 17 beta-hydroxysteroid deficiency, 5alphareductase deficiency and partial androgen insensitivity was challenging due to the primary hypogonadism. A urinary steroid profile was required to distinguish between the differential diagnoses and guide genetic sequencing.

5alpha-reductase deficiency is a rare disorder of sexual

development(3). The condition is usually autosomal recessive, as in this case, but can be compound heterozygous(4). 5alpha-reductase is responsible for the conversion of testosterone to the potent metabolite dihydrotestosterone, and deficiency leads to reduced virilisation of the male foetus. The phenotype of the external genitalia ranges widely, but female external genitalia, as in this case, is rare(2).

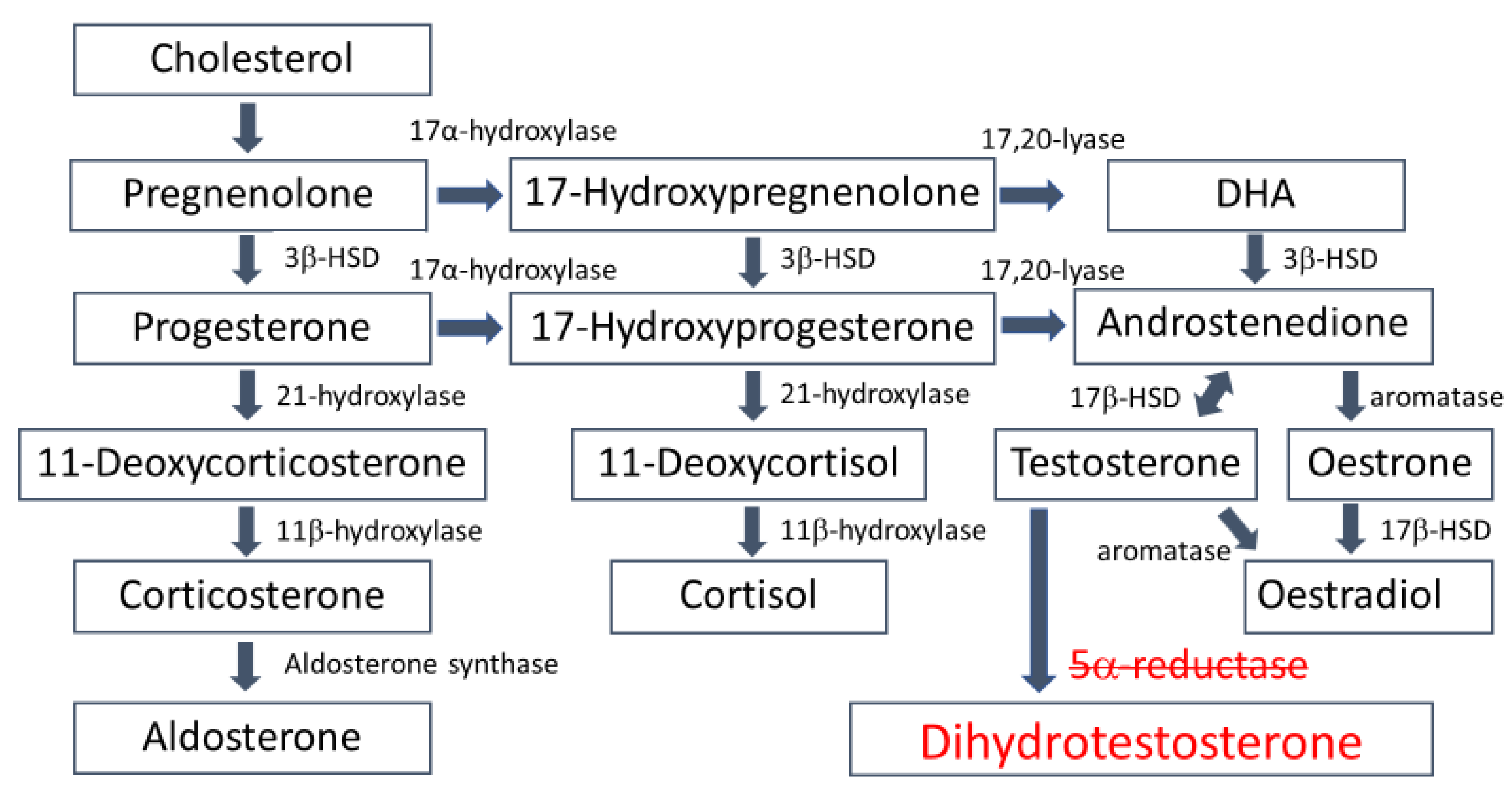

In patients with 5alpha-reductase deficiency, who are raised as female, it is reported that $56-63 \%$ change gender role to male (3); this was considered by the patient in this case. This patient experienced social and psychological challenges due her condition; this is replicated in studies which demonstrate high levels of stress and anxiety but these suggest an early diagnosis may improve psychosocial outcomes and this is reflected in management guidelines $(1,5)$.

References

1.Ahmed SF, Achermann JC, Arlt W, Balen A, Conway G, Edwards Z, et al. Society for Endocrinology UK guidance on the initial evaluation of an infant or an adolescent with a suspected disorder of sex development (Revised 2015). Clin Endocrinol (Oxf). 2015 Aug 13;84(5):771-88

2.Maimoun L, Philibert P, Cammas B, Audran F, Bouchard P, Fenichel P, et al. Phenotypical, Biological, and Molecular Heterogeneity of $5 \alpha$-Reductase Deficiency: An Extensive International Experience of 55 Patients. J Clin Endocrinol Metab. 2011 Feb 1;96(2):296-307.

3.Cohen-Kettenis PT. Gender Change in 46,XY Persons with $5 \alpha$-Reductase-2 Deficiency and 17ß-Hydroxysteroid Dehydrogenase-3 Deficiency. Arch Sex Behav. 2005;34(4):399-410. 4.Thigpen AE, Davis DL, Milatovich A, Mendonca BB, Imperato-McGinley J, Griffin JE, et al. Molecular genetics of steroid 5 alpha-reductase 2 deficiency. J Clin Invest. 1992 Sep 1;90(3):799-809.

5.D'Alberton F, Assante MT, Foresti M, Balsamo A, Bertelloni S, Dati E, et al. Quality of Life and Psychological Adjustment of Women Living with 46,XY Differences of Sex Development. J Sex Med. 2015 Jun;12(6):1440-9. 